Wayne State University

\title{
DigitalCommons@WayneState
}

Business Administration Faculty Research

Publications

Business Administration

9-1-2013

\section{The Era of Incremental Change in the Technology Innovation Life Cycle: An Analysis of the Automotive Emission Control Industry}

Jaegul Lee

Wayne State University, jaegul.lee@wayne.edu

Nicholas Berente

University of Georgia

\section{Recommended Citation}

Lee, Jaegul and Berente, Nicholas. (2013). The era of incremental change in the technology innovation life cycle: An analysis of the automotive emission control industry. Research Policy 42(8): 1469- 1481. doi: 10.1016/j.respol.2013.05.004

Available at: http://digitalcommons.wayne.edu/business_frp/1

This Article is brought to you for free and open access by the Business Administration at DigitalCommons@WayneState. It has been accepted for inclusion in Business Administration Faculty Research Publications by an authorized administrator of DigitalCommons@WayneState. 
NOTICE IN COMPLIANCE WITH PUBLISHER POLICY: This is the author's final manuscript version, post-peer-review, of a work accepted for publication in Research Policy. Changes resulting from the publishing process may not be reflected in this document; changes may have been made to this work since it was submitted for publication. This version has been formatted for archiving; a definitive version was subsequently published in Research Policy, 42(8): 14691481 (September 2013) 


\title{
The Era of Incremental Change in the Technology Innovation Life Cycle: An Analysis of the Automotive Emission Control Industry
}

\author{
JAEGUL LEE ${ }^{\mathrm{a}}$, NICHOLAS BERENTE ${ }^{\mathrm{b}}$ \\ a School of Business Administration, Wayne State University, 5201 Cass Avenue, Detroit, MI 48202, United States \\ b Terry College of Business, University of Georgia, Athens, GA, United States
}

\begin{abstract}
According to the life cycle model of technological evolution, after the emergence of a dominant design, technological product industries undergo an "era of incremental change." This era of incremental change is not well understood in the existing literature. Although the period is typically characterized in terms of stability and minimal innovation, we find that the era of incremental change can be actually quite dynamic. Through our research into the period of time following the emergence of a dominant design in automotive emission control systems, we find that the overall product innovation in the industry did not decline immediately following the dominant design, and increased throughout the era of incremental change. Further, we find that firms maintain their attention on the same core components that they innovated upon before the dominant design, but that these components make up less of the overall proportion of total innovation throughout the era of incremental change. Finally, we found that the concentration of innovating firms in the industry increases immediately following the dominant design, and this concentration decreases over time throughout the era of incremental change. Findings imply a pattern of contraction and expansion in the era of incremental change that extends previous work on the technological product life cycles and helps to characterize the era of incremental change in a novel way.
\end{abstract}

Keywords Dominant design, era of incremental change, technology life cycle, core components, automotive emission control systems

\section{INTRODUCTION}

The early stages of new technological products are marked by periods of intense innovation and competition among contending product concepts until one emerges as the "dominant design" in an industry (Anderson and Tushman, 1990). After a dominant design emerges, there is a period of relative stability that has been characterized as the "era of incremental change" (Anderson and Tushman, 1990). During this era of incremental change, the product architecture remains stable and firms transfer their attention from the overall product to innovation associated with manufacturing processes, cost reductions, component improvements, and customer segmentation (Abernathy and Utterback, 1978; Anderson and Tushman, 1990; Henderson and Clark, 1990; Funk 2003). The era of incremental change is marked by organizational, social, and political stabilization (Tushman and Rosenkopf, 1992) that stands in stark contrast to the innovative turmoil and intense standards battles that precede the dominant design (Suarez, 2004). Essentially, the level of technological innovation diminishes as firms focus on other areas of improvement (process, customer segmentation, etc.); the type of technological innovation shifts to lower (and presumably less impactful) component levels; and the concentration of firms doing the innovating increases and stabilizes (Anderson and Tushman, 1990; Tushman and Rosenkopf,
1992; Murmann and Frenken, 2006). What happens after a dominant design emerges is often seen as theoretically "uninteresting" by researchers (Dokko et al., 2012, p.682) - at least until the next technological disruption.

Recent research has found, however, that this neglected period in technological life cycles can be quite interesting - and is not as stable and incremental as was previously thought (Murmann and Frenken. 2006; Funk. 2009; Dokko et al., 2012). Take, for example, the case of the catalytic converter in automotive emission systems. In the 1970s there was an intense battle between competing standards intended to reduce pollutants from cars and fit regulatory emissions standards. Two different physical designs (dual converter and three-way) and two types of catalysts (pelleted and monolithic) were vying for the standard until the market settled on the on monolithic three-way converter architecture that has been standard for more than thirty years (Mondt, 2000; Heck and Farruto, 2002). Automotive emissions stabilized on a dominant design in 1981, and in the first twenty years after this dominant design emerged, patenting activity associated with emissions increased significantly, overall performance of emissions technologies improved by a factor of three, and the digital revolution was leveraged to enable unprecedented emissions control and tuning (King and Lyytinen, 2005; Lee et al., 2011; Lee and Berente, 2012). This level of innovation can hardly be ignored by researchers of technology innovation, and causes us to question whether the tech- 
nological innovativeness of the era of incremental change is, in fact, necessarily less than the time preceding the emergence of the dominant design (as posited by Anderson and Tushman, 1990). Also, with the focus on other innovations and improvements, does the low level of technological innovation (associated with products after a dominant design) necessarily remain stable throughout the era of incremental change? Further, given that organizational, social, and political dynamics may not stabilize in the same way that they are often characterized in the era of incremental change (Dokko et al., 2012), might the concentration of firms innovating in an industry be in greater flux than previously thought?

To address these questions and thus contribute to the literature on evolutionary lifecycles of technologies, we studied the period of time associated with the emergence of a dominant design in automotive emission control systems. We analyze patent data for the period from 1970 to 1994 and compare pre and post dominant design patterns of activity. These comparisons include: (1) the overall level of technological innovation; (2) the relative proportion of different types of component innovations; and (3) the overall concentration of firms innovating in the industry. We find that, contrary to some of the previous literature, that the overall rate of product innovation does not decrease immediately following the dominant design - and it appears to increase throughout the era of incremental change rather than stabilize or diminish. Also, firms do not immediately shift their innovative attentions away from "core" components where they focused before the dominant design. However, the overall proportion of innovation comprised by these core components does decrease over the era of incremental change. Finally, consistent with much of the literature, we find that the concentration of innovating firms increases immediately following the emergence of a dominant design, but decreases over the era of incremental change.

The remainder of the paper is organized as follows. First we briefly review the literature on the product life cycle model of technological innovation, followed by the development of our hypotheses about the nature of innovation in the era of incremental change. We then present our research into automotive emissions control systems, and conclude with a discussion of our findings.

\section{DOMINANT DESIGNS AND THE ERA OF IN- CREMENTAL CHANGE}

The product life cycle model of technological innovation (e.g. Anderson and Tushman, 1990; Utterback and Suarez, 1993) is the leading framework for research into the dynamics of product evolution over time (Murmann and Frenken, 2006). According to this view, in the evolution of technological products, there is an intense period of "ferment" whereby firms compete for dominance with their versions of new product concepts, which culminates in the emergence of a dominant design. A dominant design is a stabilized “operational principle,” or product architecture, that gains a majority of the market (Murmann and Franken, 2006). Once a dominant design emerges, there is a calm period of relative stability and incremental innovation until the next disruption. The calm period, which is referred to as the "era of incremental change" (Anderson and Tushman, 1990) has traditionally received relatively little scholarly attention.

The era of incremental change is marked by a shift from product to process innovation (Abernathy and Utterback, 1978), accompanied by a general reduction of innovativeness and a focus on cost reduction and minor component and subsystem innovation (Anderson and Tushman, 1990). These efforts can be combined with product customization for differentiated market segments and other forms of detailed, "lower level” problem solving (Funk 2003). Organizational, social, and political forces stabilize around a particular product architecture (Tushman and Rosenkopf, 1992), and firms narrow their attention to more intensely address the component technologies associated with dominant design (as opposed to innovating on the architecture, see Henderson and Clark, 1990). Because the era of incremental change is generally thought to deal with minor changes and fairly stable phenomena, the bulk of research into the technology life cycles has historically focused on technological (architectural) discontinuities and the battles for dominant design (Suarez, 2003), and often ignores the era of incremental change.

Recent work, however, has found that the era of incremental innovation is not quite so stable and uninteresting as it was (perhaps) previously thought. Incremental component innovations are often the source of the discontinuities in product architectures that result in disruptive innovations (Funk, 2009). Social and political elements of industries continue to be in a state of flux throughout the era of incremental innovation (Dokko et al., 2012). Many industries - particularly digitally intensive industries - do not exhibit the stability (associated with inverted " $U$ " shaped innovation cycles) that life cycle theory implies (Murmann and Frenken, 2006). Further, firms with products associated with a dominant design do not necessarily reduce the scope of their technology innovation efforts many maintain capabilities and continue to innovate across product levels and relevant components (Brusoni et al., 2001).

Although the era of incremental change may not be so stable and "uninteresting” (Dokko et al., 2012), there are some points upon which the literature broadly agrees. For example, when a dominant design emerges for a given product, uncertainty is reduced with respect to product architectures (the operational concepts and linkages between components) and firms do shift their attention from architectures to different innovations associated with the product (Murman and Frenken, 2006). Some of this atten- 
tion will focus on product innovation at a component ${ }^{1}$ level (Henderson and Clark, 1990), but innovative activities following the dominant design will also focus elsewhere such as on manufacturing processes. This means that the overall product innovation in this period of time will be significantly less than in the era before the dominant design, and the rate of such innovations will likewise diminish or remain minimal as this attention is spread across these different objectives (Anderson and Tushman, 1990). Further, market dynamics among firms will stabilize and solidify around shared routines, which would limit the number of new entrants (Tushman and Rosenkopf, 1992; Murmann and Frenken, 2006).

Thus we have three dimensions along which we can expect a difference between the era of ferment and the era of incremental change: the level of product innovation, the type of product (component) innovations, and the industry composition (i.e. concentration of firms). Next we will briefly attend to each dimension, followed by hypotheses derived from the extant literature.

\subsection{Level of Product Innovation}

According to the traditional view, "most of the total performance improvement over the lifetime of a technology will occur outside the era of incremental improvement" (Anderson and Tushman, 1990, p.618). After the dominant design emerges, there is a "period of inertia" characterized by network externalities, lock in, and standard interpretive frames that limit product innovations to the types that are consistent with the needs of existing customers (Kaplan and Tripsas, 2008). Once the era of incremental change commences, the amount of product innovation is thought to diminish in favor of other forms of innovation (i.e., processes, etc., Abernathy and Utterback, 1978; Anderson and Tushman, 1990; Henderson and Clark, 1990; Funk, 2003). Other forms of innovation - such as process improvement - can be leveraged across multiple products and afford greater return for firms in this period of stable product architectures (Klepper and Simon, 1997). Therefore, in the period of time following the stabilization of a product's architecture (i.e., the emergence of the dominant design) we would expect to see a lower level of overall product innovation compared to the time preceding that stabilization. From this received view, we expect the following:

Hypothesis 1a: In a technological product industry, the overall level of product innovation immediately following the emergence of a dominant design will be lower than the level of product innovation before the emergence of a dominant design.

However, as indicated above, recent work has found that the level of innovativeness in the era of incremental

\footnotetext{
${ }^{1}$ For simplicity, in this paper we use the term "component" as a generic term for any of the nested subsystems within a technological product hierarchy (Murmann and Frenken 2006).
}

change can be quite dramatic (Funk 2009; Lee and Berente, 2012). This recent work resonates with some of the case studies that found innovations in the era of incremental change to have a strong impact on product performance (Iansiti and Khanna, 1995; Christensen et al., 1998). Particularly in digitally-intensive industries (Murmann and Frenken, 2006), where the architectures are layered, openended, and generative (Yoo et al., 2010) we would expect the initially reduced level of product innovation in an industry to increase over time following the emergence of a dominant design. As large system integrating firms build capabilities on components, their suppliers attempt to move up the value chain and gain experience with architectures, and lower level components become more interesting (Brusoni et al., 2001; Funk 2009; Lee and Berente, 2012), innovative activity on technologies should accelerate over time during the era of incremental change. Thus we hypothesize:

Hypothesis 1b: In a technological product industry, the overall level of product innovation increases over time during the era of incremental change.

As far as the composition of this innovation, there is widespread agreement that after a dominant design emerges, firms will shift their attention from the overall architecture to component innovation (Henderson and Clark, 1990). However, there is little research into the shape of this component innovation and which components will be innovated upon relative to each other and over time. Next we will address the types of component innovation in the era of incremental change.

\subsection{Types of Component Innovation}

Technological products are typically conceived to be hierarchical systems, which are collections of nested, interdependent subsystems (components) coupled together by linking mechanisms (Clark, 1985; Constant, 1987; Hughes, 1987; Tushman and Rosenkopf, 1992; Murmann and Tushman, 2006). Firms cannot attend equally to each component, so their attention shifts across the product hierarchy over time as they collectively go about "working through" different components and solving key problems (Clark, 1985; pg. 243). Some of these components are more functionally significant than others, and these significant components can be expected to gain much of the early attention for technological development (Clark, 1985). Tushman and Rosenkopf (1992) describe more functionally significant components as "core" to a technology, and other, less significant components as “peripheral.” Core components are central to the operational principle of the product and peripheral components support the functions of the core components (Tushman and Rosenkopf, 1992). Murmann and Frenken (2006) use the biological concept of "pleiotropy" to distinguish between core and peripheral components of a technological product. Core components affect many functions of the product (i.e., high pleiotropy - 
such as genotypes in biology), whereas peripheral components support the core components, and have relatively fewer functions (i.e. low pleiotropy - phenotypes in biology). Core components are the tightly coupled portion that represents "a strategic performance bottleneck," and peripheral components are those that are only weakly linked to other components (Tushman and Rosenkopf, 1992). A technological product may consist of multiple core components, and it is important to note that core components of any technological product may shift over time (Tushman and Murmann, 2002). Components that were peripheral before the emergence of a dominant design may become increasingly important after product architecture has stabilized. Particularly in areas that involve digital technologies (Lee and Berente, 2012), components that previously served mainly to support other components, may evolve into a significant role in product performance. We refer to such components as "subsequent core components." A subsequent core component is a formerly peripheral component that takes a more central role in the performance of a product after the emergence of a dominant design. We contrast a subsequent core component with a "preceding core components" - the core components that were central to the product architecture before the dominant design.

In general, if one thinks of products as hierarchical systems, firms would generally shift their attention from the architecture overall to focus on the innovation of components of the product (Henderson and Clark, 1990). Core components are central elements of product architectures, and are therefore important to the competition between architectural platforms (Utterback and Suarez, 1993), but are only one of many points of competition once the architecture has stabilized. So we would expect the level of innovative activity to be high for such components before the emergence of the dominant design. After the dominant design emerges, however, firms shift their attention from architecture to more diverse components in associated with the product (Henderson and Clark, 1990; Anderson and Tushman, 1990). Thus we would expect that subsequent core components (those that were formerly peripheral) would take a proportionally greater share of the organizational attention to product innovation in the years following the emergence of a dominant design, as firms shift their attention from preceding core components. Accordingly, we would expect the following:

Hypothesis 2a: In a technological product industry, 'preceding' core components will account for less of an overall proportion (or share) of component innovations immediately following the emergence of a dominant design.

Further, Tushman and Murmann claim that "once a particular core subsystem [component] closes on a dominant design, the product's strategic action moves to another core subsystem [component] or another key dimension of merit” (2002; pg. 332). As the bottlenecks from one component are reduced, firms shift their attention to the next bottleneck, which becomes the focus of their innovative activity (Clark 1985; Tushman and Rosenkopf, 1992). The core componente important to the formation of the dominant design will then stabilize, and the attention will shift to (what were, perhaps, formerly) peripheral components. These peripheral components will benefit from selfreinforcing feedback associated with the building of capabilities within each of the components and across ever-new components and their linkages (Iansiti, 1998; Brusoni et al., 2001). Overall this will result in increasing levels of innovation over time on those peripheral components as these capabilities strengthen. Thus we expect:

Hypothesis 2b: In a technological product industry, 'preceding' core components will account for a decreasing proportion (or share) of component innovations over time during the era of incremental change.

After a product architecture stabilizes (i.e., a dominant design emerges) firms shift their attention to other elements of a product hierarchy (Clark, 1985; Henderson and Clark, 1990). Large system integrators in the industry focus their attention widely across the product architecture innovating on all sorts of components (Brusoni et al., 2001) including both preceding and subsequent core components (as well as peripheral components that remain peripheral). However, this shift in firms' attention is not necessarily uniform. Certain components - those that are increasingly important - can be expected to receive more attention. What we refer to as "subsequent core components" (components that were previously peripheral but have become more central to the architecture over time, see Tushman and Murmann, 2002) would potentially be more important than other peripheral components, and firms in the industry would look to build capabilities in such components to remain competitive. Further, although new entrants must overcome significant R\&D barriers associated with 'preceding' core components which are established by the incumbents' accumulated patents and product knowledge (Mueller and Tilton, 1969; Suarez and Utterback, 1995; Kaplan and Tripsas, 2008), these barriers will not be as entrenched for subsequent core components. New entrants would not be quite as disadvantaged in forming competencies around emerging core components that were not previously central to the architecture - the routines and patterns of activity are not yet strongly established (Kaplan and Tripsas, 2008) among subsequent core components (as compared to 'preceding' core components). Therefore, we hypothesize:

Hypothesis 2c: In a technological product industry, 'subsequent' core components will account for an increasing proportion (or share) of component innovations over time during the era of incremental change.

This hypothesis relies, to a large extent on the nature of competition in and industry and barriers to entry associ- 
ated with the emergence of a dominant design (Kaplan and Tripsas, 2008). Next we address certain related industry dynamics with respect to the concentration of firms in an industry.

\subsection{Concentration of Firms}

As indicated above, the era of incremental change is traditionally thought to involve a greater concentration of firms in an industry (Murmann and Frenken, 2006). This period of time is marked by organizational, social and political stability where routines and patterns of activity become entrenched and reinforced (Tushman and Rosenkopf, 1992), thus offering an advantage to incumbent firms (Kaplan and Tripsas, 2008). Firms associated with the dominant design "win" the battles and thus reap the rewards (Suarez, 2004) and the unsuccessful firms attempt to adapt to the new situation. These unsuccessful firms have knowledge invested in the architectures that may now be obsolete and it is no small effort to adapt and gain the new knowledge necessary to compete (Christensen et al., 1998). Therefore less agile firms end up falling out the industry, resulting in a general increase in the concentration of firms that remain. Fewer firms will be innovating in the era of incremental change - at least in the early years of the era of incremental change. From this we propose:

Hypothesis 3a: In a technological product industry, the concentration of firms innovating immediately following the emergence of a dominant design will be higher than the concentration of firms innovating before the emergence of a dominant design.

However, it is important to note that stable product architectures are accompanied by reductions in uncertainty and well-defined linkages that invite the entry of new firms, which can also involve component-level innovation (Baldwin and Clark, 2000). This implies that stable designs might actually encourage the number of firms participating in component innovation in a given industry. In addition, with the increasing importance of subsequent core component innovations, the diverse capabilities required by a new technological regime would provide opportunity for potential entrants to invest in R\&D to exploit the new market for technology (Arora et al., 2001; Greaker, 2006; Greaker and Rosendahl, 2008). Similarly, as larger firms that integrate technological products may increase their component innovation in the wake of a dominant design (Henderson and Clark, 1990), they may do so with components that are not necessarily in their core product offering - since large integrators need to maintain capabilities in a variety of interdependent components of technological products (Brusoni et al., 2001; Lee and Berente, 2012). Also, given the gaining importance of subsequent core components, the component innovations from new industry entrants can have a tremendous impact on product performance (Funk, 2009), and the innovative activities of these new entrants cannot be ignored. From this analysis we produce the following hypothesis about the concentration of firms in an industry over the era of incremental change:

Hypothesis 3b: In a technological product industry, the concentration of innovating firms decreases over time during the era of incremental change.

From our review of the literature on the era of incremental change for technological products, we developed seven hypotheses about the level of product innovations, type of component innovations, and the concentration of innovating firms in a technological product industry following the establishment of a dominant design. We test these hypotheses using data from the automotive emissions industry. Next we will briefly address this research context, followed by a presentation of our research.

\section{INNOVATION IN AUTOMOBILE EMISSION CONTROL SYSTEMS}

The evolution of automotive emission control systems (AECS) technology provides an appropriate context for examining the era of incremental change that arises after the emergence of a dominant design. In this case, the dominant design involves the standardization on a three-way catalyst-based catalytic converter architecture in 1981, which was followed by more than a decade of architectural stability until the technological shift resulting from onboard electronic diagnostic control modules in 1994 (e.g. Mondt, 2000; NESCAUM, 2000). Figure 1 depicts a simplified representation of the historical development of the AECS technologies from 1970 to 1994 . There are two distinct periods: the pre-dominant design "era of ferment" and the post-dominant design "era of incremental change." The period from 1981 to 1994 represents the era of incremental change.

\subsection{Emergence of the dominant design in AECS tech- nology}

In the 1970s, the focus of innovation in the automobile emission control system was on the catalyst technology. High automobile tailpipe emission reduction requirements mandated by the Clean Air Act Amendments in 1970 (1970 CAAA) led to the development of catalyst-based emissions reduction technology known as the catalytic converter. Initially, automakers attempted to satisfy emissions reduction requirements by modifying existing engine architecture with technologies such as exhaust gas recirculation (EGR), thermal vacuum switch (TVS), lean and rich thermal reactors, and air preheat systems (THERMAC) rather than by installing an add-in type catalytic converter which was costly and required extensive knowledge in catalysts that automakers did not possess. To automakers, a catalyst-based emission control system represented a competence-destroying technological discontinuity rather than a competence-enhancing technological discontinuity 
ANALYSIS OF THE AUTOMOTIVE EMISSION CONTROL INDUSTRY | J. LEE and N. BERENTE

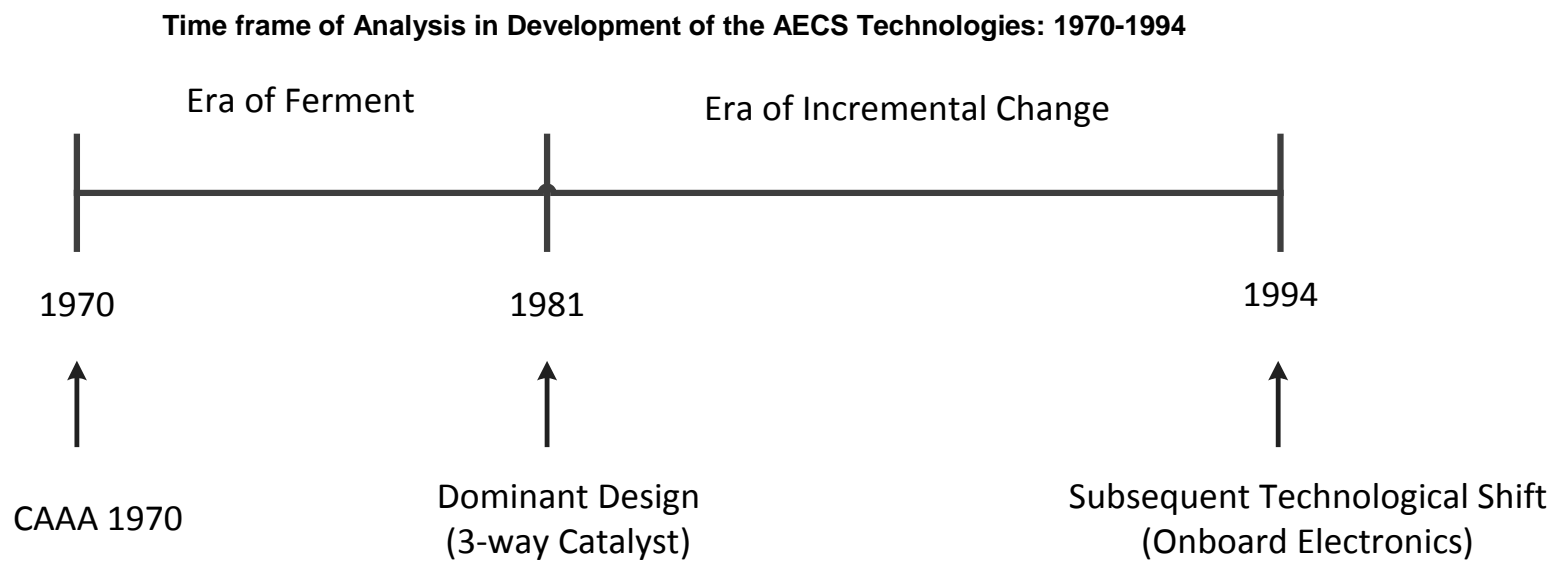

Fig. 1. Time frame of analysis in development of the AECS technologies: 1970-1994.

(Tushman and Anderson, 1986) because emissions reduction by catalyst technology would make most of their existing engine modification technologies obsolete. Honda's compound vortex controlled combustion (CVCC) engines and Chrysler's lean-burn engines, which satisfied the Environmental Protection Agency's (EPA) 1975 intermediary regulatory stringencies for hydrocarbon (HC) and carbon monoxide (CO) reduction levels (Dexter, 1979; Doyle, 2000) exemplify automakers' inclination to rely on their existing expertise when faced with technological threats (Anderson and Tushman, 1990; Cooper and Schendel, 1976). However, Honda's CVCC and Chrysler's lean-burn engines failed to satisfy nitrogen oxide $\left(\mathrm{NO}_{\mathrm{x}}\right)$ reduction requirements originally stipulated under the 1970 CAAA. Add-in type catalytic converters eventually became the only viable technical solutions for reducing all three pollutants: $\mathrm{HC}, \mathrm{CO}$, and $\mathrm{NO}_{\mathrm{x}}$ simultaneously.

Two different catalyst systems--pelleted and monolithic type catalysts--competed to gain wider acceptance among automakers (Mondt, 2000; Heck and Farrauto, 2002). Another competition for dominance during this period came between the dual converter and the three-way catalyst (TWC) system converter design (Mondt, 2000; Heck and Farrauto, 2002). These two different converter designs emerged primarily to satisfy $\mathrm{NO}_{\mathrm{x}}$ reduction standards. Firms were under pressure to develop the automobile emission control technology with improved $\mathrm{NO}_{\mathrm{x}}$ control capability that permits less than $1 \mathrm{gm}$ of $\mathrm{NO}_{\mathrm{x}}$ per mile. Reducing $\mathrm{NO}_{\mathrm{x}}$ requires lean $\mathrm{O}_{2}$ concentration, while oxidation of CO and HC needs a higher concentration of $\mathrm{O}_{2}$, which was a technical complication that proved to be a major hurdle in the development of such catalysts. The TWC system design eventually won favor because it was capable of reducing all three major pollutants (HC, CO, and $\mathrm{NO}_{\mathrm{x}}$ ) simultaneously. Engineers found a narrow range in the air-to-fuel ratio in which reduction of $\mathrm{NO}_{\mathrm{x}}$ and oxidation of $\mathrm{CO}$ and $\mathrm{HC}$ are simultaneously possible using fuel injection and sensor technologies. Eventually, the TWC converter technology using monolithic type catalysts became the dominant design for automobile emission con- trol systems in 1981, satisfying the $90 \%$ reduction requirement originally mandated in the Amendments of the Clean Air Act of 1970.

\subsubsection{Digital controls as a 'subsequent' core component}

The focus of innovation shifted, in part, to digital controls after the emergence of the catalyst-based dominant design. Indeed, firms continued to make incremental innovations in catalyst technology such as developing more durable catalysts that can withstand more severe driving conditions. Yet, the focus of innovation on digital controls grew significantly as firms recognized that the EPA would introduce another set of amendments to the Clean Air Act that required even more stringent automobile emission reductions than those of the 1970 CAAA (Lee et al., 2011). Firms eventually standardized on an advanced electronic on-board automotive diagnostic module (OBD) in 1994, and used OBD technology to satisfy new regulatory standard mandated under the Amendments to the Clean Air Act in 1990 (1990 CAAA). The introduction of the automotive OBD represents the emergence of a post-dominant design subsystem-level technological shift (Lee \& Berente 2012). An electronic onboard diagnostic system monitors all parts of the AECS including the main catalysts, thermal system, and fuel injection system through emission system sensors, and provides input signals to different part of the AECS to ensure optimal operations (Mondt, 2000).

Figure 2 illustrates the progress in performance in AECS technology from 1970 to 1994, as defined in terms of percentage improvements in pollutant ( $\mathrm{HC}, \mathrm{CO}$, and $\mathrm{NO}_{\mathrm{x}}$ ) reductions in grams per mile from the prior technology. The emergence of three technologies is shown in figure 2: oxidation catalysts, three-way catalysts, and advanced electronic control modules. Each represents technological discontinuity in 1975, dominant design in 1981, and the post-dominant design technological shift in 1994, respectively. Each introduction was accompanied by significant performance improvements. Prior to the emergence of the 
Performance Progresses in Automobile Emission Control Technologies

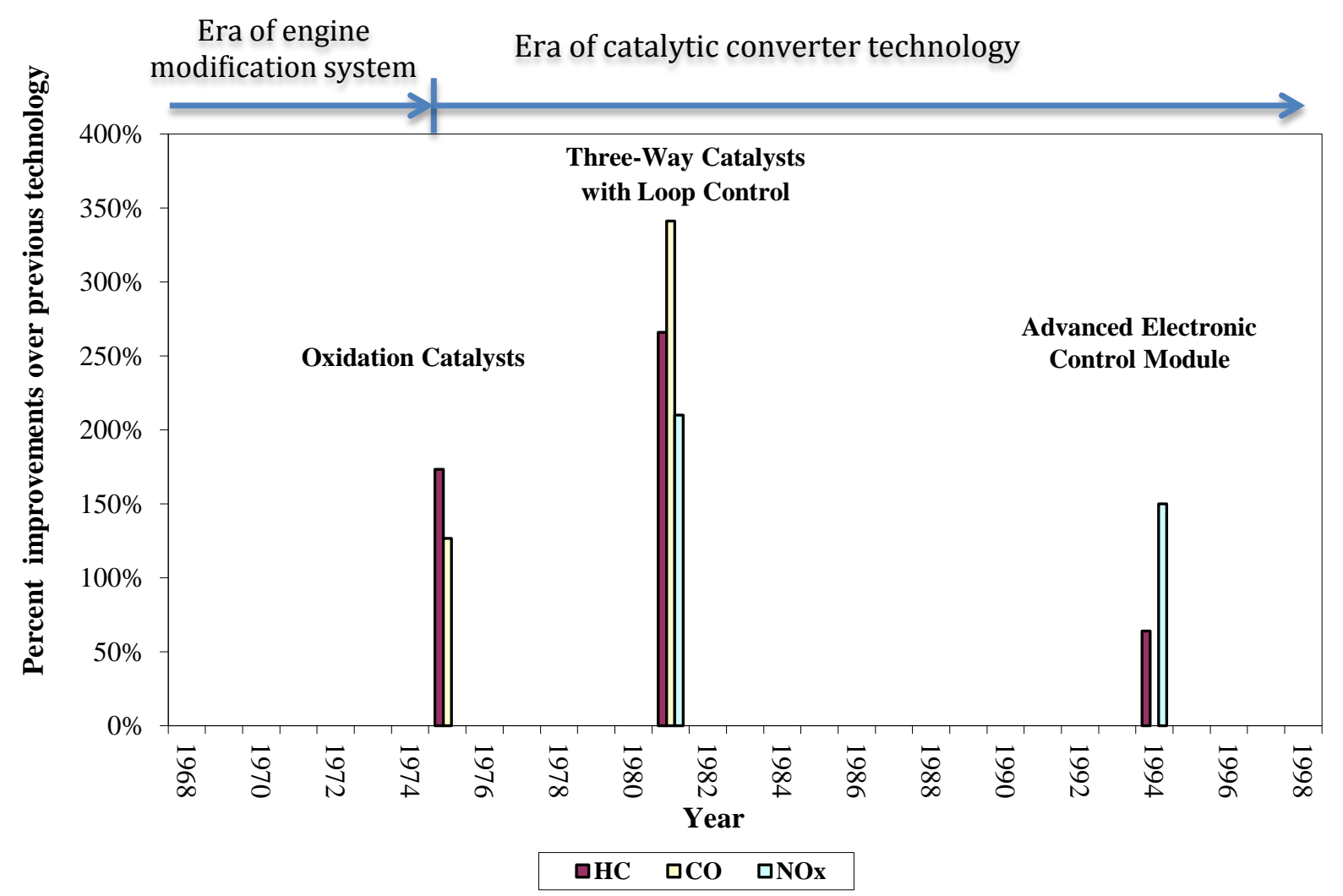

Fig. 2. Performance progresses in automobile emission control technologies

oxidation-catalyst-based catalytic converter, automakers relied on engine modification techniques to reduce auto emissions, and the introduction of catalyst-based auto emission control technology in 1975 signified an emergence of a technological discontinuity, a new technological approach for controlling auto emissions. As is shown in figure 2, its introduction brought about significant performance improvement over the previous enginemodification-based auto emissions reduction technologies.

\section{METHOD}

\subsection{Data}

To study innovation in AECS, we identified relevant patent data for AECS technology using the U.S. Patent and Trademark Office (USPTO) public database. The patent database for AECS technology was built using both the class-based and abstract-based keyword search methods. We began with the class-based search approach, adopting patent subclasses identified by Campbell and Levine's (1984) earlier study on catalytic converter technology. Moreover, we complemented the patent class search by pursuing an abstract-based search to ensure that we captured the entire set of emission control technologies for automobiles. Although a patent-class-based search allows for capturing a broad range of relevant inventions, outdated patent classes identified by an earlier study would not fully capture the breadth of AECS technologies that have evolved. The abstract-based search, which identifies relevant patents by using representative keywords, thus complements the class-based search. The abstract-based search helped us identify relevant patents not found by the classbased search. For the abstract-based search we selected seven keywords that represent AECS technologies - catalytic converter, emission, automobile, catalyst, pollution, exhausts, and engine - and searched the USPTO patent database electronically by using various combinations of these keywords. We also closely examined the abstracts of all identified patents to further screen for catalytic converter technology that does not belong to automotive applications from the database. Patent data has some limitations as a measure of innovation, and patents certainly do not capture the entirety of innovation in an industry (Scherer 1983, Griliches 1990, Acs et al. 2002; Kerr and Shihe, 2008). However, patent as a data is highly correlated to the extent of the firm's innovation activities (Trajtenberg 1989), and the automotive industry relies heavily on patenting. Further, patent data, with all its limitations, does allow for a detailed longitudinal analysis of the process of technical change in a way that few other datasets can (Almeida et al. 2002; Katila, 2002). 


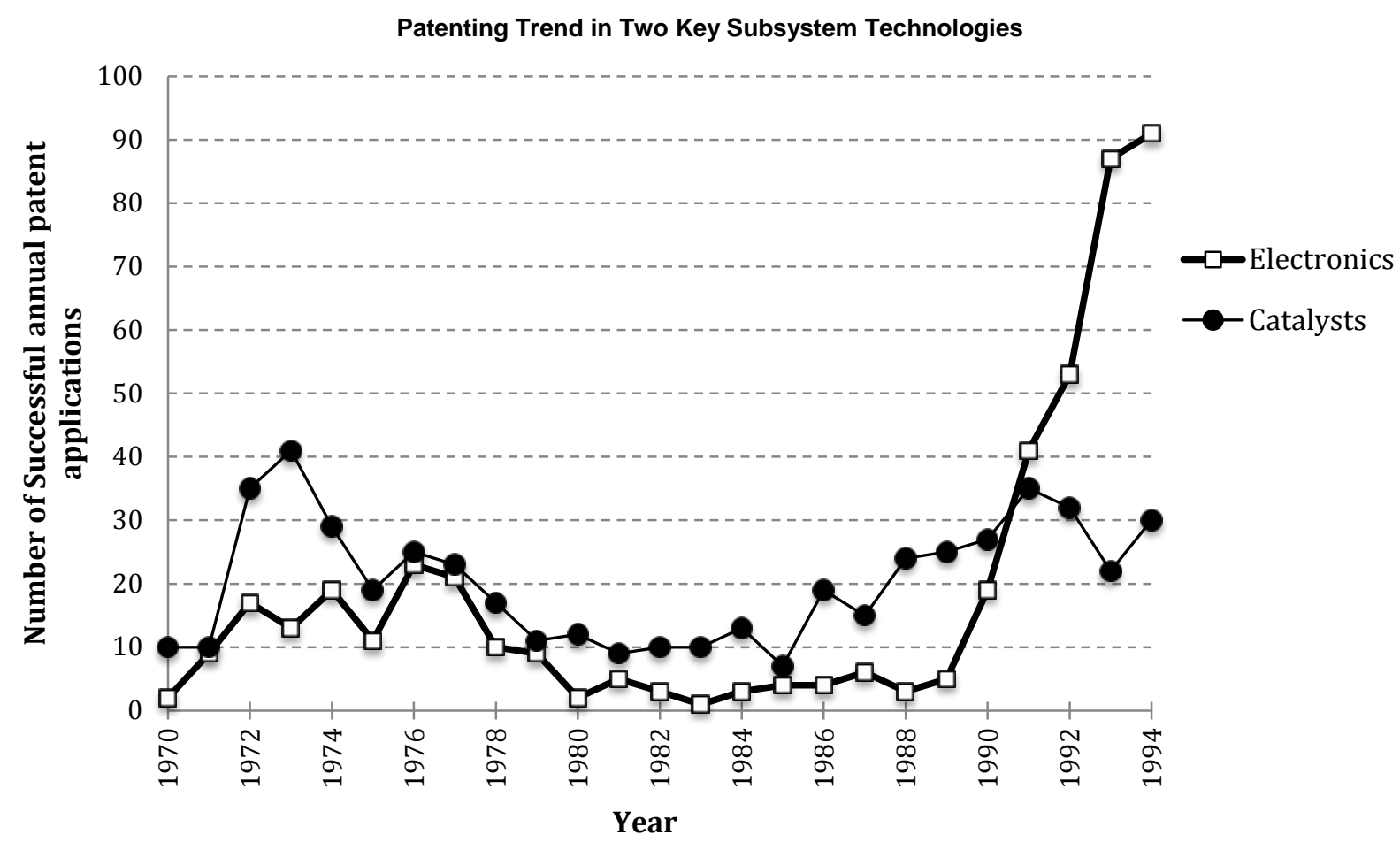

Fig. 3. Patenting trend in two key subsystem technologies.

The total number of successfully applied patents relevant to AECS technologies assigned to firms from 1970 to 1994 is $1,429 .^{2}$ We further categorized the carefully screened and identified AECS patents into three subtechnology categories - catalysts, digital controls, and manufacturing - to specifically examine the era of incremental change. The AECS technologies that belong to catalyst categories include catalyst support materials, palladium three-way catalysts, and porous catalyst carriers. Those that belong to the digital controls category included air to fuel ratio control, EGR control, and various types of sensors. Manufacturing AECS technologies include the assembly method for catalytic converter and catalytic converter housing design.

The first author possesses deep technical knowledge of the auto emissions control technology and used his knowledge for categorizing AECS patents into the three different categories. ${ }^{3}$ Nevertheless, his patent coding was cross-checked by an independent coder to establish independent justification of the coding scheme. We used the period from 1980 to 1994 for this study since this time period captures the beginning of the development of the AECS technology in 1970 to the emergence of a post dominant design technological shift in digital controls: the onboard diagnostic module in 1994 (marking the end of that era of incremental change).

\footnotetext{
${ }^{2}$ Detailed information regarding identified patents and corresponding

patent classes is available from the authors upon request.
${ }^{3}$ The first author has extensive industry experience as an automotive

patent classes is available from the authors upon request.
${ }^{3}$ The first author has extensive industry experience as an automotive technical engineer in a major automaker.
}

\subsection{Dependent variables}

There are three different dependent variables for this study: (1) the level of product innovation (H1a and H1b), (2) the proportion of different types of component innovations (H2a, H2b and H2c) and (3) the concentration of innovating firms (H3a and H3b). We measured the level of product innovation using the number of successful annual patent applications in two key component [subsystem] technologies (catalyst and digital controls). These two component technologies are the ones that became the core components over the evolution of the auto emissions control technology-- catalyst technology was the core subsystem technology responsible for the emergence of the dominant design in 1981 (catalytic converter technology, i.e., the 'preceding' core component) and digital controls technology was the subsequent core component technology responsible for the emergence of the onboard diagnostic system in 1994. Patenting trend data in the two key component technologies is plotted in figure 3.

The proportion of subsystem technology in a given year was measured by dividing the number of subsystem technology patents by the overall patent counts in the AECS technology in that particular year. Specifically, we measured the proportion for catalyst and digital controls subsystem technologies.

To construct the concentration of innovating firms measure, we used the Herfindahl-Hirschman Index (HHI) (Hall, 2005) as below: 


$$
\text { HHI of innovating firms }=\sum_{i=1}^{n} S_{i}^{2}
$$

where $S_{i}$ represents the patent share of firm $i$ in the auto emissions control technology field, and $N$ is the number of patenting firms.

\subsection{Independent and control variables}

We used two variables to estimate the dynamic effects of the dominant design. First, we created a dominant design dummy variable to capture the effect of the establishment of a dominant design in 1981. We coded one for period between 1981 to1994, and refer to this variable as the era of incremental change. Second, we created a time trend variable to capture the dynamic effects of the dominant design during the post dominant design period, that is, whether the dominant design effect increase or decrease over time. This time trend variable is equal to zero from 1970 to 1980 and counts the number of years starting from 1981 when the dominant design was established. Therefore, time trend variable indicates whether the size of the main effect increases or decreases over time during the era of incremental change.

We added a number of control variables: expenditure, auto sales, patenting in auto electronics and patenting in total auto technologies, to account for potential factors that may also affect innovation in AECS. First, we included in the equation capital expenditures for emission control for light-duty vehicles (expenditure) to control for the potential impact of industry capital expenditures on innovation in the development of the automobile emission control devices. Because government regulations such as the Clean Air Acts of 1970 and 1990 were among of the major factors influencing the firms' R\&D decisions (including the industry capital expenditure in complying with the regulation particularly), expenditures effectively control for the potential impact of the regulations on innovative activity. Industry capital expenditures on automobile emission control devices are estimated using the data provided by the Environmental Protection Agency and the California Air Resource Board (EPA, 1990; CARB, 1996). Both the EPA (1990) and CARB (1996) reports provide cost estimates with a detailed breakdown of components of the emission control systems such as evaporative emissions canisters, exhaust gas recirculation units, universal exhaust oxygen sensors, full electronic EGR system, close-coupled catalysts, electrically heated catalysts, leak-free exhaust systems, engine modifications such as improved piston ring and head gasket design, and electric air injection system. The EPA's (1990) study reveals that by 1994, auto emission devices approximately cost an additional $\$ 475$ per vehicle to achieve $90 \%$ of tailpipe emission reductions from the pre 1970 emission level. Further study using the data from the US Bureau of Labor Statistics shows that the cost of the emission control system further increased due to the phase-in of the Tier I standards in 1994 (Anderson and Sherwood, 2002).
We also controlled for potential market forces in the development of the AECS technology by including a variable that captures US retail car sales (Auto Sales). We used Ward's automotive publication to obtain US retail car sales data (Ward's Auto, 2010). Firm innovation in the development of the AECS technology can be affected by an overall innovation trend in the automobile industry - and in this case there was widespread component innovation in digital technologies and electronics in the 1980s and 1990s due to the digital revolution. Thus, we also included the total patent counts in automotive electronics technology as a control (Auto Patents) to capture any potential effect that patenting in electronics auto emission control technology reflects overall patenting activities in automotive electronics technologies and thus do more to isolate the impact of the technology lifecyle. We used the United States Patent Classification (USPC) to obtain annual patent counts in automotive digital controls technologies. Patent classes used to search automotive digital controls technologies include 307/101.1 (automotive transmission or interconnection systems) and 315/77 (electric discharge devices for vehicles) ${ }^{4}$.

\subsection{Statistical method}

Because the dependent variable for H1a and H1b (Product innovation) consisted of patents of two key component technologies, we used a negative binomial specification. The negative binomial panel regression is well known to account for the count nature of patent data and repeated cross-sectional observation a period of time would be appropriate (Hausman et al., 1984). As the data for this study consisted of a panel of observations for firm patenting activities over multiple years (1970-1994), a negative binomial specification is deemed appropriate. For regressions that involve non-count fractional dependent variables (Proportion of innovation and Firm concentration), we used the generalized linear model (glm) regression technique. The generalized linear model is known to account for the properties of non-normally distributed variables such as proportion based on counts whose values fall between zero and one (McCullagh and Nelder, 1989). We also report results with robust standard errors using the Huber-White estimator for variance.

To further build robustness into our analysis and complement pooled regressions, we ran additional firm fixedeffects panel regressions for H1 (Product innovation) and H2 (Proportion of component innovation). The advantage of using fixed-effects regression is that it controls for unobservable firm-level heterogeneities that are not accounted for in the regression model such as firms' propensity for patenting their ideas (Pavitt, 1985) and firms' capabilities such as technological investments and strategies (PennerHahn and Shaver, 2004; Arundel and Kabla, 1998). For the fixed-effect panel regressions, we used the patent data of

\footnotetext{
${ }^{4}$ Full patent classes used to search patents in auto electronics technologies are available from authors upon request
} 
ANALYSIS OF THE AUTOMOTIVE EMISSION CONTROL INDUSTRY | J. LEE and N. BERENTE

Table 1

Descriptive Statistics of variables used for analyses.

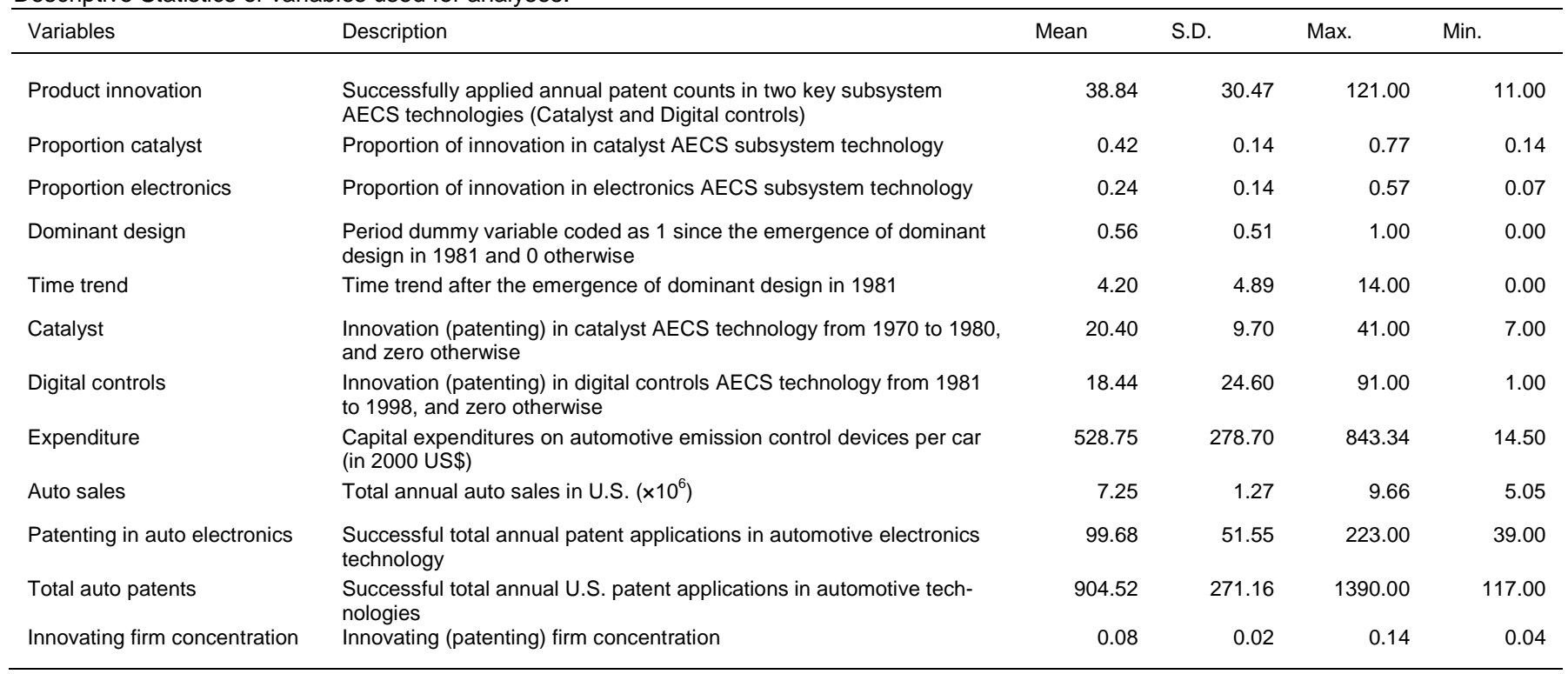

Table 2

Correlations matrix.

\begin{tabular}{|c|c|c|c|c|c|c|c|c|}
\hline & \multirow[t]{2}{*}{ Variables } & \multicolumn{7}{|l|}{$n=1429$} \\
\hline & & 1 & 2 & 3 & 4 & 5 & 6 & 7 \\
\hline 1. & Time trend & & & & & & & \\
\hline 2. & Catalyst & $0.34^{*}$ & & & & & & \\
\hline 3. & Digital controls & $0.67^{*}$ & $0.48^{\star}$ & & & & & \\
\hline 4. & Expenditure & $0.73^{*}$ & -0.12 & $0.26^{*}$ & & & & \\
\hline 5. & Auto sales & $-0.56^{*}$ & 0.01 & $-0.27^{*}$ & $-0.54^{*}$ & & & \\
\hline 8. & Dominant design & $0.78^{*}$ & -0.06 & $0.22^{*}$ & $0.85^{\star}$ & $-0.62^{*}$ & $0.53^{*}$ & $0.64 *$ \\
\hline
\end{tabular}

Note. Correlation for non-interacting independent variables is not reported.

$$
\text { * } p<0.05 \text {. }
$$

the top fifteen patenting firms: five automakers (General Motors, Toyota, Ford, Nissan, and Honda) and ten component suppliers (Engelhard, W.R. Grace, Corning, Nippondenso, EMITEC GmBH, NGK insulators, Robert Bosch, Universal Oil Production Company, Hitachi, and SIEMENS).

\section{RESULTS}

Tables 1 and 2 show descriptive statistics and the correlation matrix for variables used to test the hypotheses. Table 2 shows that some variables are highly correlated. High correlations among variables are known to cause significant muliticollinearity; thus, bias regression estimates (Kennedy, 1985). To ensure that our regressions do not suffer from potential multicollinearity problems, we calculated the variable inflation factor (VIF) for all regression model specifications. None of the calculated VIFs was found to be higher than 10, which indicates that regression models in this study do not suffer from harmful collinearity (Kennedy, 1985).
Table 3 and 4 reports results of tests for hypotheses. Table 3 reports regression results using the pooled dataset while table 4 reports regression results using the panel dataset. We also report log likelihoods (table 3) and chisquares (table 4) at the bottom of the table.

For both table 3 and table 4, model 1 and model 2 show the regression results using product innovation (i.e., the level of overall product innovation) as the dependent variable. Similarly, model 3 through model 6 display the regression results using proportion of component innovations (i.e., catalyst technologies as 'preceding' core component and electronics technologies as 'subsequent' core component) as the dependent variables. For table 3, model 7 and model 8 show the results using innovating firm concentration as the dependent variable. In both tables (table 3 and table 4), dominant design and time trend are predictor variables; and auto sales, expenditures, total auto patents and auto electronics patents are control variables. In particular, auto electronics patents are specially added in model 6 to control for potential impact that patenting in overall automotive electronics may have on firm patenting 
ANALYSIS OF THE AUTOMOTIVE EMISSION CONTROL INDUSTRY | J. LEE and N. BERENTE

Table 3

Pooled regression results.

\begin{tabular}{|c|c|c|c|c|c|c|c|c|}
\hline \multirow[t]{5}{*}{ Dependent variables } & \multicolumn{2}{|c|}{ Product innovation } & \multicolumn{4}{|c|}{ Proportion of subsystem technology } & \multicolumn{2}{|c|}{ Innovating firm concentration } \\
\hline & \multirow{4}{*}{$\begin{array}{l}\text { Model } 1 \\
1970-1983 \\
\mathrm{Yr}_{\mathrm{DD}}+2\end{array}$} & \multirow{4}{*}{$\begin{array}{l}\text { Model } 2 \\
1970-1994\end{array}$} & \multicolumn{2}{|l|}{ Catalyst } & \multicolumn{2}{|l|}{ Digital Controls } & \multirow{4}{*}{$\begin{array}{l}\text { Model } 7 \\
1970-1983 \\
\mathrm{Yr}_{\mathrm{DD}}+2\end{array}$} & \multirow{4}{*}{$\begin{array}{l}\text { Model } 8 \\
1970-1994\end{array}$} \\
\hline & & & Model 3 & Model 4 & Model 5 & Model 6 & & \\
\hline & & & $1970-1983$ & 1970-1994 & 1970-1994 & 1970-1994 & & \\
\hline & & & \multicolumn{4}{|l|}{$\mathrm{Yr}_{\mathrm{DD}}+2$} & & \\
\hline Dominant design & $-0.68(0.97)$ & $-1.36^{\star \star \star \star}(0.29)$ & $0.27^{\star \star \star \star}(0.03)$ & $0.27^{\star \star \star}(0.10)$ & $-0.19^{\star \star}(0.08)$ & $-0.29^{\star \star \star}(0.10)$ & $0.02^{\star \star}(0.01)$ & $0.003(0.01)$ \\
\hline Time trend & $0.39(0.63)$ & $0.23^{\star \star \star \star}(0.02)$ & $\begin{array}{l}-0.19^{\star \star \star \star} \\
(0.03)\end{array}$ & $-0.03^{\star \star \star}(0.01)$ & $0.04^{\star \star \star \star}(0.01)$ & $0.05^{\star \star \star}(0.01)$ & $-0.01(0.01)$ & $\begin{array}{l}-0.002^{*} \\
(0.001)\end{array}$ \\
\hline Log (Auto sales $\left.\left(1 / 10^{3}\right)\right)$ & $2.03^{\star \star}(0.83)$ & $0.60(0.65)$ & $-0.13(0.16)$ & $0.17(0.19)$ & $0.08(0.11)$ & $-0.03(0.12)$ & $-0.02(0.05)$ & $-0.02(0.03)$ \\
\hline Log (Expenditure) & $-0.02(0.10)$ & $-0.06(0.14)$ & $-0.02(0.02)$ & $-0.02(0.03)$ & $0.005(0.02)$ & $0.03^{*}(0.02)$ & $0.01(0.01)$ & $0.01(0.01)$ \\
\hline Auto electronics patents $\left(1 / 10^{3}\right)$ & & & & & & $-1.42(1.23)$ & & \\
\hline Total auto patents $\left(1 / 10^{3}\right)$ & $-0.27(0.57)$ & $-0.66^{\star *}(0.31)$ & $0.05(0.08)$ & $0.03(0.12)$ & $-0.31^{\star \star}(0.10)$ & & $-0.02(0.03)$ & $-0.03(0.02)$ \\
\hline Intercept & $-0.45(1.91)$ & $3.02^{\star}(1.75)$ & $0.72^{\star \star}(0.33)$ & $0.12(0.41)$ & $0.25(0.26)$ & $0.21(0.26)$ & $0.1(0.14)$ & $0.11(0.07)$ \\
\hline$N$ & 624 & 1429 & 624 & 1429 & 1429 & 1429 & 624 & 1429 \\
\hline Log Likelihood & -48.72 & -95.53 & 15.18 & 19.28 & 25.74 & 23.84 & 32.5 & 65.98 \\
\hline
\end{tabular}

$\mathrm{Yr}_{\mathrm{DD}}$ (the year the dominant design in AECS technology emerged) $=1981$

* $p$-Value $<0.1$, two-tailed tests.

** $p$-Value $<0.05$, two-tailed tests.

$\star \star \star \quad p$-Value $<0.01$, two-tailed tests.

$* * * * \quad p$-Value $<0.001$, two-tailed tests.

Table 4

Panel Regression Results

Dependent variables

\begin{tabular}{|c|c|c|c|c|c|}
\hline \multicolumn{2}{|c|}{ Product innovation } & \multicolumn{4}{|c|}{ Proportion of subsystem technology } \\
\hline \multirow{2}{*}{$\begin{array}{l}\text { Model } 1 \\
1970-1983\end{array}$} & \multirow{4}{*}{$\begin{array}{l}\text { Model } 2 \\
1970-1994\end{array}$} & \multicolumn{2}{|l|}{ Catalyst } & \multicolumn{2}{|l|}{ Digital Controls } \\
\hline & & Model 3 & Model 4 & Model 5 & Model 6 \\
\hline \multirow[t]{2}{*}{$\mathrm{Yr}_{\mathrm{DD}}+2$} & & $1970-1983$ & 1970-1994 & 1970-1994 & 1970-1994 \\
\hline & & $\mathrm{Yr}_{\mathrm{DD}}+2$ & & & \\
\hline $0.2(0.94)$ & $-1.38 *(0.29)$ & $0.05(0.03)$ & $0.03(0.02)$ & $-0.02 *(0.01)$ & $-0.03^{\star \star}(0.10)$ \\
\hline$-0.18(0.64)$ & $0.26^{\star \star \star \star}(0.04)$ & $-0.03(0.03)$ & $-0.002(0.002)$ & $0.005^{\star \star \star}(0.002)$ & $0.004^{\star \star \star}(0.001)$ \\
\hline $1.70 \star *(0.76)$ & $0.71(0.62)$ & $-0.02(0.04)$ & $0.02(0.02)$ & $0.02(0.02)$ & $0.003(0.01)$ \\
\hline \multirow[t]{2}{*}{$0.09(0.08)$} & $0.03(0.08)$ & $0.002(0.004)$ & $0.001(0.004)$ & $0.0005(0.004)$ & $0.002(0.004)$ \\
\hline & & & & & $-0.13^{*}(0.08)$ \\
\hline $2.85^{\star}(1.61)$ & $-1.01(0.74)$ & $0.06(0.06)$ & $0.003(0.05)$ & $-0.04^{*}(0.02)$ & \\
\hline$-5.24^{\star \star \star}(1.76)$ & $-0.67(1.13)$ & $0.004(0.05)$ & $-0.03(0.03)$ & $0.01(0.03)$ & $0.01(0.03)$ \\
\hline 201 & 375 & 210 & 375 & 375 & 375 \\
\hline $20.83^{\star \star *}$ & $141.23^{\star \star \star}$ & 8.23 & $11.70^{\star \star}$ & $10.74^{\star}$ & $10.98^{*}$ \\
\hline
\end{tabular}

${\text { Wald } \mathrm{Chi}^{2}}_{\mathrm{Yr}_{\mathrm{DD}} \text { (the year the dominant design in AECS technology emerged) }=1981 .}$

$\mathrm{Yr}_{\mathrm{DD}}$ (the year the dominant design in $\mathrm{A}$
$* \quad p$-Value $<0.1$, two-tailed tests.

$\begin{aligned} & * \quad p \text {-Value }<0.1 \text {, two-tailed tests. } \\ & * * \quad p \text {-Value }<0.05, \text { two-tailed tests. }\end{aligned}$

*** $p$-Value $<0.01$, two-tailed tests.

$\star \star \star * \quad p$-Value $<0.001$, two-tailed tests.

11 DIGITALCOMMONS@WSU | 2013 
behaviors in electronics automotive emissions control technologies.

In hypothesis1a, we argued that the overall level of product innovation in an industry is lower immediately after the emergence of a dominant design for a technological product. To test hypothesis $1 \mathrm{a}$, we examined the coefficient for the dominant design dummy in model 1, table 3 and 4. To operationalize patenting activities immediately after the emergence of the dominant design, we examined the coefficient of the dominant design dummy for the first two years after the emergence of a dominant design (model 1). ${ }^{5}$ The coefficient is negative and insignificant for the regression using the pooled dataset. Similarly, fixed-effects regression results using the panel dataset (model 1, table 4) also show that, the dominant design dummy coefficient for the first two years is insignificant. Consequently, these findings together disconfirm hypothesis $1 \mathrm{a}$.

In hypothesis 1b, we hypothesized that for a technological product, the overall level of product innovation in an industry increases over time during the era of incremental change. To test hypothesis $1 \mathrm{~b}$, we examined the time trend variable in model 2, table 3 and 4 . The time trend variable is positive and significant $(p<0.001)$ for model 2 in both the pooled and firm fixed-effects regressions (table 3 and 4). Thus, this finding confirms the hypothesis $1 \mathrm{~b}$ that the overall level of product innovation increases over time after the emergence of a dominant design for a technological product.

In hypothesis 2a, we proposed that the core subsystem, which became the dominant design accounts for less of an overall proportion of innovation immediately after the emergence of a dominant design. To test hypothesis 2a, similarly we examined the coefficient for the dominant design variable for the proportion of catalyst subsystem for the first two years in model 3, table 3 and 4 . The catalyst subsystem is the 'preceding' core component. Contrary to our prediction, the coefficient is positive and this finding is consistent across the two different dataset (table 3 and 4). Thus, these findings indicate that the proportion of innovations associated with the preceding core component increased $^{6}$ rather than decreased immediately after the emergence of a dominant design. Consequently, there is no support for hypothesis 2a.

In hypothesis 2b, we hypothesized that for a technological product, the proportion of innovation associated with the preceding core component (i.e. catalysts) declines over time during the era of incremental change. To test

\footnotetext{
${ }^{5}$ Two years was deemed an appropriate amount of time to operationalize patent applications as a measure for the level of innovation based on the assumption that it takes roughly 11 months to file a patent application. So the first year would capture work in anticipation of the dominant design and the first and second years would capture work immediately following the dominant design. After two years it is more than two cycles of patenting out from the dominant design, which can no longer be considered "immediately following." This is particularly relevant in fast-changing industries such as digital electronics.

${ }^{6}$ Based on the positive and significant $(p<0.001)$ regression coefficient for the dominant design dummy variable in model 4 , table 3.
}

hypothesis $2 \mathrm{~b}$, we examined the coefficient for time trend variable in model 4 , table 3 and 4 . For the pooled regression (table 3 ), the coefficient is negative and significant ( $p$ $<0.05$ ). However, for the fixed-effects regression (table 4 ), the coefficient for the time trend variable is negative as expected but insignificant. Thus, we argue that hypothesis $2 \mathrm{~b}$ is weakly supported as there is partially significant support the hypothesis.

In hypothesis 2c, we predicted that for a technological product, the proportion of innovation associated with a subsequent core component increase over time during the era of incremental change. To test hypothesis 2c, we examined the coefficient of the time trend variable for electronics subsystem in model 5 and 6 in both table 3 and 4. The electronics subsystem is the subsequent core component during the era of incremental innovation. As predicted, the time trend variable for electronics subsystem is positive and significant $(p<0.05)$ for both model 5 and model 6 . Importantly, model 6 has patenting in auto electronics technology as a control and the time trend variable is still significant $(p<0.05)$, indicating that this overall increase in emissions electronics is over and above the trend in automotive electronics in general. This finding is consistent in both the pooled and fixed-effects regressions. Consequently, there is significant support for hypothesis 2c.

In hypothesis $3 a$ and $3 b$, we focus on changes in the innovating firm concentration for a technological product during the era of incremental innovation. In hypothesis 3a, we proposed that the concentration of innovating firms is higher immediately following the emergence of a dominant design; and to test hypothesis 3a, we examined the coefficient for the dominant design dummy in model 7, table 3. As expected, the regression coefficient is positive and significant $(p<0.05)$, confirming the hypothesis 3a. Moreover, the time trend variable in model 8 is negative and significant $(p<0.1)$ confirming the hypothesis $3 b$, which predicted that the concentration of innovating firms in the industry decreases over time in the era of incremental change.

The regression coefficients for control variables, industry capital expenditures, automotive sales and total auto patents appear to be largely insignificant, suggesting that controls are only weakly related to overall product innovation or innovation in key subsystem technologies in the development of automotive emissions control technologies. Table 5 below is a summary of the models, hypotheses and findings, followed by a discussion of these results.

\section{DISCUSSION}

Drawing on existing research into the "era of incremental change” in technological product lifecycles (Anderson and Tushman 1990), we develop and test hypotheses that imply a dynamic model of innovative activity in an industry in a period of time following the establishment of a dominant design. This model essentially breaks up this time period into two segments: (1) the period of time immediately fol- 


\section{ANALYSIS OF THE AUTOMOTIVE EMISSION CONTROL INDUSTRY | J. LEE and N. BERENTE}

Table 5

Summary of findings.

Models and

hypotheses

Model 1 - Level of Product Innovation: Immediately Following Dominant Design

$\mathrm{H1a} \quad$ In a technological product industry, the overall level of product innovation immediately following the emergence of a dominant design will be lower than the level of product innovation before the emergence of a dominant design.

Model 2 - Level of Product Innovation: Over Time

$\mathrm{H} 1 \mathrm{~b}$

In a technological product industry, the overall level of product innovation increases over time during the era of incremental change.

Model 3 - Types of Component Innovation: Immediately Following Dominant Design

$\mathrm{H} 2 \mathrm{a} \quad$ In a technological product industry, 'preceding' core components will account for less of an overall proportion (or share) of component innovations immediately following the emergence of a dominant design.

Model 4 - Types of Component Innovation: Over Time

$\mathrm{H} 2 \mathrm{~b}$

In a technological product industry, 'preceding' core components will account for a decreasing proportion (or share) of component innovations over time during the era of incremental change.

Models 5 and 6- Types of Component Innovation: Over Time

$\mathrm{H} 2 \mathrm{C}$

In a technological product, 'subsequent' core components will account for an increasing proportion (or share) of component innovations over time during the era of incremental change.

Model 7- Concentration of Innovating Firms: Immediately Following Dominant Design

$\mathrm{H} 3 \mathrm{a}$

In a technological product industry, the concentration of firms innovating immediately following the emergence of a dominant design will be higher than the concentration of firms innovating before the emergence of a dominant design.

Model 8 - Concentration of Innovating Firms: Over Time

$\mathrm{H} 3 \mathrm{~b}$

In a technological product industry, the concentration of innovating firms decreases over time during the era of incremental change.
Findings

Not Supported

- Pooled: not supported

- Fixed effects: not supported ${ }^{\text {a }}$

Supported

- Pooled: supported

- Fixed effects: supported

Not Supported

- Pooled: not supported ${ }^{\mathrm{b}}$

- Fixed effects: not supported ${ }^{a}$

Weakly Supported

- Pooled: supported

- Fixed effects: not supported

Supported

- Pooled: supported

- Fixed effects: supported

Supported

\footnotetext{
${ }^{a}$ The coefficient was in the opposite direction (positive or negative) than hypothesized, but insignificant

${ }^{\mathrm{b}}$ The coefficient was in the opposite direction (positive or negative) than hypothesized and significant.
}

lowing the establishment of the dominant design (H1a, H2a, H3a); and (2) over time until the next technological shift (H1b, H2b, H2c, and H2d). We apply this model to three different aspects of innovative activity: the level of overall product innovation; the relative types of component innovation; and the concentration of innovating firms in the industry. Findings are mixed for the automotive emission control industry in the period of time immediately following the standardization on the catalytic converter design, but they generally support hypotheses over time. Next we will discuss each of these three aspects of the innovative activity in the era of incremental change and the implications for research.

\subsection{Overall Level of Product Innovation}

We expected overall product innovation to pull back after a dominant design, as certain elements of the product design are stabilized and firms pursue other avenues for innova- tion - avenues that potentially provide more return, such as manufacturing processes (Klepper and Simon, 1997). However, we expected this reduced level of product innovation should increase over time. Our findings support the increase over time, but do not support the pull-back in the overall level of product innovation in the early years of the era of incremental change. Thus, overall innovation on technological products in the era of incremental change may not be less than during the era of ferment - which is often implied by many researchers who study technology life cycles. Of course, one may argue that product innovations after a dominant design are smaller and more incremental - less radical than those before the dominant design. This is certainly the case to some extent - because architectures are stabilized so the innovative activity on an architectural level is diminished in favor of modular innovations (Henderson and Clark, 1990). However, these modular, or within-component / subsystem innovations are not necessarily minor - and many of the manufacturing tech- 
nologies and other areas of innovation may require complementary product improvements. For example, in his study of Rolls Royce's aircraft engine manufacturing, Prencipe (1997) found that after the dominant design was established, there was intense investment in a variety of interrelated innovations for the next 15 years in materials, component designs, and manufacturing processes, which were all complementary. New alloys enabled the wide chord fan blade, for example, which required new manufacturing processes (Prencipe, 1997). Such interrelated, complementary product innovations only become more intense in situations that evolve the evolution of digital technologies such as digital controls. Digital control innovation brings with it a higher degree of interdependency with other components when compared to non-digital sorts of controls (such as hydraulic engine control systems, Brusoni et al., 2001). Further, digital technologies are programmable and generative (Yoo et al., 2010) which allows for interactions and complementarities across the entire product architecture outside of the modular interfaces between architectural components (Lee and Berente, 2012). These innovative elements of digital technologies can be important to innovation during the time frame of our study - it is precisely this time period where electronics innovations transformed the automotive industry (King and Lyytinen, 2005). We controlled for automotive electronics in our analysis (as well as a variety of other variables - including automotive innovation overall), and our results clearly appear to indicate that the stage in a technology's life cycle may not matter to overall innovation in quite the way others have thought in the past. These results are more in line with those studies that found the era of incremental change to be abundant with impactful innovation (Prencipe 1997; Murmann and Frenken 2006; Funk 2009; Lee et al 2011; Dokko et al 2012). The question then became - what was the composition of this innovative period of time? We addressed this question by exploring the relative types of component innovation in automotive emissions.

\subsection{Types of Component Innovation}

The automotive emissions control industry provided a particularly valuable sample because there are fundamentally only two types of components: those associated with the catalyst, and those associated with digital controls. The catalyst was the sole core component before the emergence of the dominant design (what we describe as 'preceding' core component) - and during this time digital controls were peripheral. After the dominant design emerged, digital controls also became core to the innovative activity in automotive emissions. When a component goes from peripheral to core over time, we refer to this as a 'subsequent' core component (in relation to the 'preceding' core component). Thus our two sets of components enable us to isolate the relative patterns of movement associated with preceding and subsequent core components.

Although the movement of innovative activity from certain core components to others has been characterized in the literature (Tushman and Rosenkopf 1993; Prencipe 2000; Murmann and Frenken 2006), there is no broad empirical analysis showing how this happens over the course of the era of incremental change. The literature indicates that after a dominant design the relative magnitude of innovative activity would focus on more diverse product components (Henderson and Clark 1990; Anderson and Tushman 1990), implying that the overall proportion of preceding core component innovation would diminish immediately following the dominant design. Our findings do not support and actually contradict these expectations. The relative share of innovative activity on preceding core components does not diminish immediately after the dominant design - but does diminish (as a relative proportion of overall innovation) over time. This finding implies that core components may not necessarily become less important to innovative activity once a product architecture is stabilized because firms maintain knowledge across components even as overall product structures stabilize (Prencipe et al., 2003). However, although the proportion of innovation on preceding core components does not diminish immediately following the dominant design (quite the contrary - it increases!), it does account for relatively less of the overall product innovation over time, just as the subsequent core components account for more over time. This finding supports the idea that firms shift their innovative attention from previous to subsequent core components over time after the emergence of a dominant design. These findings are consistent with expectations that firms focus on more diverse components over time (Henderson and Clark, 1990; Anderson and Tushman, 1990) and that firms generally need to maintain competencies across a variety of components (Brusoni et al., 2001). Of course, this composition of innovating activities in an industry will have some relationship to the concentration of firms in that industry, which we will discuss next.

\subsection{Concentration of Innovating Firms}

In our findings, there was a higher concentration of innovating firms immediately following the emergence of a dominant design - a finding consistent with the idea of an industry "shake-out" where the winners in the innovation battle remain and the losers depart the industry (Klepper 1996; Utterback and Suarez 1993; Suarez 2003). Over time, however, due to the stabilization and resulting certainty associated with the product architecture, this concentration diminishes as new entrants make increasing impacts on the product (Funk 2009). Two factors can explain this increase. First, dominant designs inevitably increase the degree of modularity of a technology product - even if that product is not entirely modular - and therefore one would expect the patterns of innovative activity following a dominant design to be consistent with the literature on modular innovations (Argyres and Bigelow, 2010). This finding is consistent with the work that identifies specific conditions when industry shakeout does not occur over time - these include situations that are quite consistent with the modu- 
larity argument, but do not focus on product architectures, and instead focus on industry effects such as "vertical separation" of appropriability (Bonaccorsi and Giuri 2001) and degree of partitioning in the network (Bonaccorsi and Giuri 2000). Second, in this case the subsequent core components involve digital technologies. Digital technologies require different capabilities for their design and development - including capabilities involving software programming - from the sorts of things incumbent firms have done in the past (Brusoni et al 2001; Yoo et al., 2012). Clearly many of these new capabilities will be provided by new entrants to previously non-digital industries such as the automotive industry in the 1980s.

\section{CONCLUSION}

The era of incremental change in a technological product's life cycle may not be as 'uninteresting' as it is often characterized in the literature. In this research, we take a step towards unpacking the patterns of innovative activity in this period of time that follows the emergence of a dominant design. Although in certain areas the era of incremental change behaves as expected - like with the initial shake-out of the industry and eventual decrease in concentration of innovators following the dominant design - in other areas findings may be surprising. For example, the overall level of product innovation did not decrease after the dominant design - nor did the relative attention to core components. This is a step we take - along with a handful other recent studies (e.g., Funk, 2009; Dokko et al., 2012) in paying more attention to the era of incremental change.

\section{ACKNOWLEDGEMENTS}

This research benefited from the support of the National Science Foundation (NSF \#522190), the International Motor Vehicle Program (IMVP), and the Center for the Study and Improvement of Regulation (CSIR) at Carnegie Mellon University. We would like to thank Francisco Veloso, David Hounshell, Edward Rubin, David Gerard, and Amrit Tiwana for their helpful comments.

\section{REFERENCES}

Abernathy, W. J., Utterback, J. M., 1978. Patterns of Industrial Innovation. Technology Review 80, 40-47.

Acs, Z. J., Anselin, L., Varga, A., 2002. Patents and innovation counts as measures of regional production of new knowledge. Research Policy 31, 1069-1085.

Almeida, P. J., Song, J., Grant, R., 2002. Are firms superior to alliances and markets? An empirical test of cross-border knowledge building. Organization Science 13, 147-161.

Anderson, J. F., Sherwood, T., 2002. Comparison of EPA and other estimates of mobile source rule costs to actual prices changes. SAE 2002-01-1980, Washington, DC.
Anderson, P., Tushman, M. L., 1990. Technological discontinuities and dominant designs: a cyclical model of technological change. Administrative Science Quarterly 35, 604-633.

Argyres, N., Bigelow, L., 2010. Innovation, modularity, and vertical deintegration: evidence from the early U.S. auto industry. Organization Science 21:842-853.

Arora, A., Fosfuri, A., Gambardella, A., 2001. Markets for Technology: The Economics of Innovation and Corporate Strategy, MIT Press, 2001.

Arundel, A., Kabla, I., 1998. What percentage of innovations are patented? empirical estimates for european firms. Research Policy 27, 127-141.

Baldwin, C. Y., Clark, K.B., 1997. Managing in an age of modularity. Harvard Business Review 75, 84-93.

Bonaccorsi, A., Giuri, P., 2001. The long-term evolution of vertically-related industries. International Journal of Industrial Organization 19, 1053-1083.

Bonaccorsi, A., Giuri, P., 2000. When shakeout doesn't occur: The evolution of the turboprop engine industry. Research Policy 29, 847-870.

Brusoni, S., Prencipe, A., Pavitt, K., 2001. Knowledge specialization, organizational coupling, and the boundaries of the firm: why do firms know more than they make? Administrative Science Quarterly 46, 597-612.

Campbell, R. S., Levine, L. O., 1984. Technology Indicators Based on Patent Data: Three Case Studies, Battelle Pacific Northwest Laboratory.

CARB, 1996. Low-Emission Vehicle and Zero-Emission Vehicle Program Review. Sacramento, CA, Mobile Division, California Air Resource Board.

Christensen, C. M., Suarez, F. F., Utterback, J. M., 1998. Strategies for survival in fast-changing industries. Management Science 44, S207-S220.

Clark, K. B., 1985. The interaction of design hierarchies and market concepts in technological evolution. Research Policy $14,235-251$

Constant, E. W., 1987. The social locus of technological practice: community, system, or organization? In: Bijker, W. E., Hughes, T. P., Pinch, T. (Eds.), The Social Construction of Technological Systems. Cambridge, MA, The MIT Press.

Cooper, A. C., Schendel, D., 1976. Strategic responses to technological threats. Business Horizons 19, 61-69.

Dexter, D., 1979. Case Study of the Innovation Process Characterizing the Development of the Three-way Catalytic Converter System. Lexington Technology Associates. Lexington, MA,

Dokko, G., Aigam, A., Rosenkopf, L., 2012. Keeping steady as she goes: a negotiated order perspective on technological evolution, Organization Studies 33, 681-703

Doyle, J., 2000. Taken for A Ride. Four Walls Eight Windows. New York.

EPA, 1990. Environmental Investiments: The Cost Of a Clean Environment, United States Environmental Protection Agency, EPA-230-1 1-90-083.

Funk, J. 2009. Components, systems and discontinuities: the case of magnetic recording and playback equipment. Research Policy 38, 1192-1202.

Greaker, M., 2006. Spillovers in the development of new technology: a new look at the Porter hypothesis. Journal of Environmental Economics and Management 52, 411-420.

Greaker, M., Rosendahl, K. E., 2008. Environmental policy with upstream pollution abatement technology firms. Journal of Environmental Economics and Management 56, 246-259. 
Griliches, Z. 1990. Patent statistics as economic indicators: A survey. Journal of Economic Literature 28,1661-1707.

Hall, B. 2005. A note on the bias in Herfindahl-type measures based on count data. Revue d'Économie Industrielle, 110, 149-156.

Hausman, J., Hall, B. H., Griliches, Z., 1984. Econometric models for count data with an application to the patents - R\&D relationship. Econometrica 52, 909-938.

Heck, R. M., Farrauto, R. J., 2002. Catalytic Air Pollution Control: Commercial Technology. New York, NY; John Wiley \& Sons, Inc.

Henderson, R. M., Clark, K. B., 1990. Architectural innovation: the recognition of existing product technologies and the failure of established firms. Administrative Science Quarterly 35, 9-30.

Hughes, T. P., 1987. The evolution of large technological systems. In: W. E. Bijker, T. P. Hughes, Pinch, T., The Social Construction of Technological System. Cambridge, MA, The MIT Press.

Iansiti, M., 1998. Technology Integration. Boston, MA, Harvard Business School Press.

Iansiti, M., Khanna, T., 1995. Technological evolution, system architecture and the obsolescence of firm capabilities. Industrial and Corporate Change 4, 333-361.

Katila, R., 2000. New product search over time: Past ideas in their prime? Academy of Management Journal 45, 995-1010.

Kaplan, S., Tripsas, M., 2008. Thinking about technology: applying a cognitive lens to technical change. Research Policy 37, 790-805.

Kennedy, P., 1985. A Guide to Econometric Methods. Cambridge, MA, MIT Press.

Kerr, W., Shihe, F., 2008. The survey of industrial R\&D - patent database link project. The Journal of Technology Transfer, 33, 173-186.

King, J.L., K. Lyytinen. 2005. Automotive informatics: Information technology and enterprise transformation in the automobile industry. In: W.H. Dutton, B. Kahin, R. O’Callaghan, A.W. Wychoff, (Eds.), Transforming Enterprise: The Economic and Social Implications of Information Technology. MIT Press, Boston, MA.

Klepper S., Simons K.,1997. Technological extinctions of industrial firms: an inquiry into their nature and causes. Industrial and Corporate Change, 6, 379-460.

Klepper, S. 1996. Entry, exit, growth, and innovation over the product life cycle. The American Economic Review 86, 562583.

Lee, J., Berente, N., 2012. Digital innovation and the division of innovative labor: digital controls in the automotive industry. Organization Science, Forthcoming

Lee, J., Veloso, F. M., Hounshell, D., 2011. Linking induced technological change, and environmental regulation: Evidence from patenting in the U.S. auto industry. Research Policy.

McCullagh, P., Melder, J. A., 1989. Generalized Linear Models (2nd eds). Boca Raton, FL: Chapman \& Hall/CRC.

Mondt, J. R., 2000. Cleaner Cars: The History and Technology of Emission Control Since the 1960s, Society of Automotive Engineers.

Murmann J. P., Frenken K., 2006. Toward a systematic framework for research on dominant design, technological innovations, and industrial change. Research Policy 35, 925-952

Mueller, D. C., Tilton, J. E., 1969. Research and development costs as a barrier to entry. The Canadian Journal of Economics 2, 570-579.
NESCAUM, 2000. Environmental Regulation and Technology Innovation: Controlling Mercury Emissions from Coal-Fired Boilers, Northeast States for Coordinated Air Use Management.

Pavitt, K. 1985. Patent statistics as indicators of innovative activities: possibilities and problem. Scientometrics, 7, 77-99.

Penner-Hahn J., Shaver J. M., 2004. Does international research and development increase patent output? An analysis of Japanese pharmaceutical firms. Strategic Management Journal 26, $121-140$

Prencipe, A. 1997. Technological competencies and product's evolutionary dynamics: a case study from the aero-engine industry. Research Policy 25, 1261-1276.

Prencipe, A. 2000. Breadth and depth of technological capabilities in CoPS: the case of the aircraft engine control system. Research Policy 29, 895-911.

Prencipe, A., Davies, A., Hobday, M., 2003. The Business of Systems Integration, Oxford University Press.

Scherer, F. M. 1983. The propensity to patent. International Journal of Industrial Organization, 1, 107-128.

Suarez, F. F., Utterback, J. M., 1995. Dominant designs and the survival of firms. Strategic Management Journal 16, 415-430.

Suarez, F. F., 2004. Battles for technological dominance: an integrative framework. Research Policy 33, 271-286.

Trajtenberg, M., 1989. The welfare analysis of product innovations with an application to computed tomography scanners. Journal of Political Economy 97, 444-479.

Tushman, M. L., Anderson, P., 1986. Technological discontinuities and organizational environments. Administrative Science Quarterly 31, 439-465.

Tushman, M., Murmann, J. P., 2002. Dominant designs, technology cycles and organizational outcomes. In: Garud, R., Kumaraswamy, A., Langlois, R. N., Malden, M. A., Managing in the Modular Age: Architectures, Networks, and Organizations., Blackwell.

Tushman, M., Rosenkopf, L., 1992. Organizational determinants of technological change: toward a sociology of technological evolution. Research in Organizational Behavior 14, 311-347.

Utterback, J. M., Suarez, F. F., 1993. Innovation, competition and industry structure. Research Policy 22. 1-21.

Ward's Auto, 2010. Ward's Motor Vehicle Facts and Figures. Ward's Communications. Southfield, MI.

Yoo, J., Henfridsson, O., Lyytinen, K., 2010. Research commentary - the new orga- nizing logic of digital innovation: an agenda for information systems research. Information Systems Research 21, 724-735.

Yoo, J., Boland Jr., R.J., Lyytinen, K., Majchrzak, A., 2012. Organizing for innovation in the digitized world. Organization Science 23, 1398-1408. 